\title{
Is sickle cell disease sufficiently prioritized in policy and socio-economic research on diseases in Tanzania? Lessons for the past 50 years
}

\author{
GODFREY M. MUBYAZI ${ }^{*}$ and KATO J. NJUNWA ${ }^{2}$ \\ ${ }^{1}$ National Institute for Medical Research (NIMR), P.O Box 9653 Dar es Salaam, Tanzania \\ ${ }^{2}$ Kigali Health Institute, Faculty of Community Health Development, Kigali, Rwanda
}

\begin{abstract}
Catastrophic health consequences associated with chronic and genetic disorders, including those related to sickle cell disease (SCD) remain lowly measured and understood. Illnesses associated with SCD, especially the, sickle cell anaemia (SCA) pose significant tolls to individual patients and their families and contribute to poverty due to loss in production and retardation of economic development. This paper synthesises evidence from systematic literature reviews on policy priorities both in theory and practice and studies carried out on SCD. The review was systematically done by drawing evidence from published and unpublished literature searched through online search engines and other sources. The magnitude of SCA problem is yet to be adequately measured and documented in terms of the scale of its prevalence in many countries including Tanzania. However, a few reports available pinpoint Tanzania as one of the African countries with a large number of patients with SCD. Social stigma and discrimination against patients with SCD pose psychological affect to either the individual patients or their family members and this is partly due to low community knowledge on this disease on one hand and the perceived socio-economic disturbances associated with the disease that at times reduce the morale of caregivers/takers in families to attend patients. A few studies so far seem to have much focused on the medical dimensions of the disease usually reported at health facilities therefore, failing to establish the actual magnitude and socio-economic consequences of the disease, thus limiting the room for more informed policy decisions. Unfortunately, the inadequate public policy and research attention to this disease indicates that there is need for revisiting research and policy agenda towards making a difference in its interventions, and this include creation of public awareness and prioritizing research.
\end{abstract}

Keywords: sickle cell, anaemia, neglected diseases, family health, genetic disorders, Tanzania

\section{Background}

Focus of most disease-related socio-economic studies and programmes in developing countries seem as if they have been over-driven by policy decision orientation to communicable diseases such as malaria HIV/AIDS, tuberculosis, diarrhoeal diseases, and others that affect larger proportions of the populations in terms of causing high rates of morbidity and mortality in the community. These diseases are the ones that at least have had special programmes that have drawn policy attention to allocate enormous amounts of resources to manage and control them. Thus, little attention has been paid to direct policy decisions on research and interventions geared for addressing diseases of chronic nature (Aikins et al., 2010). Unfortunately, chronic diseases cause regrettable financial and economic burdens as well as catastrophic biological health consequences to the effected individuals and their families, especially when they affect the individuals from the poor and marginalized families.

Sickle cell disease (SCD), has thus, been one of the chronic diseases neglected for a long time in Tanzania as in many other countries' health ministries within Africa (Grosse et al., 2011). Illnesses associated with SCD, especially the commonest form of it - sickle cell anaemia (SCA) pose significant tolls to individual patients and their families or relatives and contribute to poverty by leading to loss in productive time and money on the side of the affected persons/families and retardation of their economic development, but this has remained a mere fact to be widely documented systematically. One of the noted gaps is the a general shortage of studies focusing on financial, economic and psychosocial costs dimensions associated with SCD problems while the policy on this disease and the commitment to practice is not much clear in

*Correspondence: Dr. Godfrey M. Mubyazi; E-mail: gmmubyazi@yahoo.co.uk; mubyazig@hotmail.com 
many countries of Africa, as reported from the developed countries of the western world (Haque \& Telfair, 2000). This paper, therefore, synthesises evidence from a systematic literature review on policy priorities in theory and practice/implementation and studies undertaken so far in relation to SCD in Tanzania, emphasis being on policy advocacy and practice as well as psychosocial and economic costs borne by SCD patients and their families. It finally identifies agenda for policy and research action for Tanzania and where possible to be considered as lessons elsewhere in the world.

\section{Methodology}

At least 66 articles (over 90\% being published) were reviewed for the evidence presented in the present paper. The review was systematically done by drawing evidence from published and unpublished literature. This was done by using appropriate key words to search through the internet, visiting some libraries physically, requesting technical reports or published copies of the relevant articles directly from some of the authors. To obtain the online literature through the internet, various search engines were used. These included PubMed/Medline, Google and HINARI. This was made possible by typing the relevant key words in the search sites. Search words included sickle-cell, anaemia, chronic diseases, socio-economic, sickle-cell and knowledge/awareness/perceptions/attitudes, Tanzania and a combination thereof. This approach has been used before in other reviews (Mubyazi et al., 2008).

The abstracts displayed were read carefully and key points taken before the decision was made on whether or not to read the whole paper for inclusion in the review. Some articles were sought from the websites of the journals with the access online. The co-authors agreed to search the literature required separately/independently without influencing each other, then coming to have a common agreement on which ones seemed relevant to include in the review considering the review topic and objectives. Then the review process continued according to the agreed guidelines/format by exchanging the points reviewed by each to share comments that were compiled by the principal author. Surprisingly, no article published in the 1960 s and 1970 s could be accessed online using the search engines identified. Therefore, this made it difficult to state how many studies were carried out during such periods and the themes studied. For the published papers that were accessed online, interest was in the most relevant articles those published from 1961-2011, covering 50 years of Tanzania's independence. The unpublished literature, including technical research or consultancy reports, newspapers, scientific powerpoint presentations, and conference proceedings were also included in the review.

\section{Historical Perspective of Sickle Cell Disease}

Until 2010, it was a hundred years since the first report on sickle haemoglobin (HbS) was reported in the world and that the gene responsible for this disorder could reach high frequencies because of resistance conferred against malaria by the heterozygous carrier state (Piel et al., 2010). SCD is a genetic and mostly an inheritable disorder - and one of the chronic diseases in humans (Martin \& Soldo, 1997; Cochrane Library 2009). According to a recent paper by Burchanan et al., (2010), "Patients with sickle cell disease have abnormal haemoglobin that polymerizes under physiologic conditions, leading to the formation of distorted and rigid red blood cells. This in turn causes haemolysis and obstruction of blood flow in the microcirculation, with resultant tissue ischemia and necrosis. Pain and organ injury are the sequelae".

Thus, essentially the SCD originates from an abnormal type of haemoglobin called haemoglobin ( $\mathrm{Hb}) \mathrm{S}$, (abbreviated as $\mathrm{HbS}$ ) that changes the shape of red blood cells, especially when the cells are exposed to low oxygen levels, therefore, taking the shape of a crescent or a sickle. Another name of $\mathrm{HbS}$ is SCA, referring to homozygous individuals as opposed to heterozygous individuals abbreviated as HbAS (Harvard University, 2002). The most common 
types of sickle cell disease are SS, SC and S beta thalassemia while others but of more rare forms include SD-Punjab, SOArab, SLepore and SE disease (IDH: http://www.idph.state.il.us/HealthWellness/SickleCell.pdf; Anie et al., 2010).

The gene for SCA is widespread all over the world, but with much more concentration in Africa, Mediterranean countries, the Middle East and parts of India (Anie et al., 2010). Specialists have established that in the event when both parents are carriers of sickle cell trait or another haemoglobin change (like haemoglobin C), there is 1 in 4 (a 25\%) chance for them to have a child with SCD. Such couple also has a $25 \%$ chance of having a child with regular haemoglobin (AA) and a $50 \%$ chance of having a child with a haemoglobin trait like the parents. For this reason, it is recommended for people who carry a haemoglobin trait to meet a genetic counsellor to obtain more information, and this would be much helpful before people enter into marriage (IDPH: http://www.idph.state.il.us/HealthWellness/sicklecell.htm).

The patient with SCA develops into full-blown, serious disease by inheriting the defect from both of their parents who have the defective gene (Creation Ministries International, 1994). Marriage, religious and social habits contribute passing this disease from the parents to the offspring, among other factors (Martin \& Soldo 1997). SCA patients live with troublesome health conditions caused by $\mathrm{HB}$ polymerization and its resultant red blood cell (RBC) deformation (sickling) under a reduced oxygen tension (Brugnara et al., 2001). The patient experience painful extremities, severe haemolytic anaemia, acute oliguric renal failure (Kalyanaraman et al., 1999; van den Tweel et al., 2008), and may even experience stroke if the sickled RBCs block blood vessels in the brain (Vichinsky et al., 2002; Cochrane Library 2009). Pain and disabilities are the central features of SCD (Aikins et al., 2010) and the main clinical manifestation are due to both anaemia and vaso-occlusive events and patients suffering from vaso-occlusive events are the normally said to be in sickle cell crises (Zieve \& Chen 2011).

There is no cure for SCD but with early detection of the disease, accompanied by proper medical care, affected children can survive up to the age of 42 (Brown, 2010) or between 40 and 45 years (www.chartcaribbean.org/careofplwa/pdfdcs) or even up to 52 years and beyond (Cochrane Library 2009). It is sad that people with SCD may suffer from life-long disorders and according to experts these are characterized by recurrent and unpredictable episodes of haemolytic anaemia, anaemia crises stroke, infections, other conditions, as well as numerous problems related to organ dysfunctioning of varying severity (Jenerette \& Lauderdale, 2008). The disease is distributed in all continents around the world, and in Europe reports show that it is increasingly becoming common due to demographic changes (Hijmans et al., 2009, 2010). It is estimated that of the children born with SCD in the world, 75-80\% are born in Africa (Sadarangani et al., 2009; Brown, 2010; Makani et al., 2011). However, the magnitude of the prevalence of SCD in Africa needs further analysis due to overlapping statistics reported from different evaluations and in different periods. For instance, Fleming (2009) states that in total, about 120,000 children in Africa are born with SCD each year; Diallo (2008) reports that between 150,000 and 300,000 homozygous individuals are born each year in Africa. Previous estimates show that about 200,000 newborns in Africa were affected with the disease (Diallo \& Tchernia, 2002); Makani et al., (2009) report that approximately 280,000 children are born with SCA in Africa; other reporters reveal that globally 300,000 babies are born with sickle cell (Anie et al., 2010). This indicates that even at country level, records on the prevalence of this disease may be different and confusing. Reports on SCD prevalence continue being updated from time to time, and therefore, users of the reports should be careful to take note of the source of and reliability of the information obtained. For instance, more recently, it has been reported that over $90 \%$ of people living with SCD in the world are of African ancestry and the prevalence of the sickle cell trait ranges between $10-40 \%$ of the population in some parts of Africa. Meanwhile the trait is relatively more concentrated among some ethnic groups, for instance, 35\% and 50\% among some tribes in Uganda and Tanzania, respectively (Martin \& Soldo, 1997). In other countries such as Cameroon, Republic of Congo, Gabon, Ghana and Nigeria, prevalence lies between $20 \%$ and $30 \%$. 
SCA in particular, is fatal in the very early age of human's life if not immediately diagnosed and management is assured. It is estimated that $50-80 \%$ of all the current number of patients will die before adulthood (Makani et al., 2011). The most vulnerable age group is the under-fives (Makani et al., 2011). However, the vulnerability to death of the patients with SCD may depend on other factors (Tshilolo et al., 2007). SCD is prevalent in different parts of the world, especially in SSA region, Asia and South and Central America (Jenerette \& Lauderdale, 2008). In these countries, a considerable proportion of the population also present some sickle cell traits even if they are asymptomatic (Weatherall \& Clegg, 2001). The geographical distribution of the sickle cell trait is quite similar to that of malaria and the main reason being that sickle cell trait has a partial protective effect against malaria and that is why it has maintained high levels of prevalence in some parts of tropical Africa (WHO, 2009).

Furthermore, the clinical characteristics of children with SCD in the African Region are described by relatively few studies. This means that the disease is still lowly known by the general public and even among a considerable number of health professionals. That is, the descriptions of the natural history and clinical spectrum of SCD in Africa are surprisingly scarce and this contributes to most of the treatment recommendations for the management of this disease remain based on studies conducted in resource-rich countries (Sadarangani et al., 2009). In the context of lack skills or equipment and other supplies for carrying out proper diagnosis, the risk of patients to lack appropriate treatment and management of their cases, and the risk of facing death immediately, are very likely to happen (WHO, 2009). Misdiagnosis due to lack of either the technical knowledge or other facilities or both the knowledge/skills and facilities is likely to affect treatment procedures and outcomes (Golden \& Moore 2004; Howard 2006).

SCA, as one condition among other conditions of SCD is usually associated with high levels of health care utilization, and this affects the individual patients, health departments and governments (Mvundura et al., 2009). According to various experts in the area of chronic diseases, the economic impact of SCD on families, health systems and governments is immense. To the individuals and their families, the medical and psychological costs of managing the disease/patient both directly and indirectly are regrettably high since the patient live with the disease and costs are spread or faced throughout the life-span of the patients (Buchanan et al., 2011). Meanwhile, the relationships between national policy making and international economic and political pressures have a huge impact on the risk of SCD and other chronic diseases and the ability of countries to respond to them (Aikins et al., 2010).

The course of illness attacks caused by SCA to patients especially children is unpredictable, this placing a heavy strain on the affected children and their families. Also, besides the medical problems associated with this disease, most families with SCD patients have to cope with negative social beliefs and financial problems related to this disease (Diallo \& Tchernia, 2002; Jenerette \& Lauderdale 2008; Hijmans et al., 2009). Thus, taking care of a patient with SCD especially a child poses extra demands on parents especially those living in low socio-economic status, both practically and psychologically, which turning into emotional problems, may influence their quality of life (van den Tweel et al., 2008). Occurrence and recurrence of illness episodes facing SCA patients pose psychological, financial and economic costs to the subjects, considering the pain such people face and either themselves or their families/relatives when it comes to need for seeking medical care. From the moral perspective, the psychological effects of this disease to the patients and their families are serious and warrant humanistic interventions (Hijmans et al., 2009). SCD like other chronic diseases such as asthma, cancer, and diabetes cause disruptions to the physical capabilities, social identities and life trajectories of the sufferers and may lead to impoverishment of the sufferers and their families. They are associated with chronic unhappiness, spiritual distress, psychiatric disturbance, and sometimes suicidal ideation. Such psychological, emotional and spiritual disruptions can occur even within the context of strong family support and often undermine social and medical relationships and illness management and self-care. Furthermore, adult persons suffering from any one of the chronic diseases including 
SCD may find themselves in a situation whereby they have to sacrifice paying medical care costs for their children by having to meet the costs of their own sufferings. Such patients may also lose time for participation in economic activities during the period in which they are responding to illness episodes (Gil et al., 1997; Jenerette \& Lauderdale, 2008; Aikins et al., 2010; Anie et al., 2010). The chronic anaemia and recurrent acute painful vaso-occlusive crises which occur unpredictably require immediate management and this becomes a great burden and challenge to families whereby the caretakers/givers are themselves living in poor states and vulnerable to other health problems (van den Tweel et al., 2008).

There are a number of reports concerning the stigma and discrimination faced by the victims of this disease in the society (Anie et al., 2010), and this is confirmed further by one source of evidence quoting a 23 years student of Business Administration at a particular university in East Africa responding to the researchers: "People used to mock me, they say why study while you have SCD and you will die soon, it hurts but I said to myself I am going to fight this disease" (Brown, 2010). From the financial and economic perspective, the costs are regrettably high. For instance, apart from the time and financial costs faced on travelling and waiting for medical care services at the clinics, the patients and or their families may find themselves facing enormous costs if they still have to pay for the medical services.

\section{Past, Current and Future Interventions}

It has been established that unfortunately once the SCD has occurred, it is unpreventable, and instead prevention can mainly be achieved through continuous health education to the communities sensitizing them and undertaking screening to identify the carriers, coupled with premarital counselling. These measures have been adopted in some Mediterranean countries (Al Arrayed, 2005) and in developed countries (Weatherall \& Clegg, 2001), but to a large part of the African Region.

The World Health Organization (WHO) recently declared SCD as a public health priority (WHO 2005, 2006; Makani et al., 2007, 2011). However, it is still not clear about the extent to which resource-poor countries including those in Africa have taken appropriate steps to plan and implement interventions aimed at addressing this problem in the past, what is being done at present and what is planned to be done in the future. To be able to manage the disease effectively, it is imperative to know it properly and provide the necessary diagnostic, treatment and management services. Although there is no universal cure of SCD in the world (Annie et al., 2010), the principles of management and control have already been laid out and therefore it is up to the individual country stakeholders responsible to consider their positions for applying them in their own contexts.

The goal of treatment is to limit the frequency or number of crises. Patients with SCD need to undergo treatment continuously even when they are not in crisis. Moreover, adult patients and caretakers/givers of children and adults who cannot serve themselves are advised to keep adequate fluid (e.g. drinking water and juices) with them and avoid exposing the patients to too much intense sunlight; avoid strenuous activities, stress events that reduce oxygen level, smoking, and high altitudes and non-pressurized flights (Zieve \& Chen 2011). Depending on the facilities and human resource skills available, the treatment of the complications for the SCD may include kidney dialysis or kidney transplant for kidney disease, drug rehabilitation and counselling for psychological complications, gall-bladder removal in those with gallstone disease, hip replacement for vascular necrosis of the hip, surgery for persistent-painful erections, surgery for eye problems, wound care, giving zinc oxide or surgery for leg ulcers. Another option could be bone marrow transplant or stem cell transplants to cure SCA. However, these are not currently emphasised or used for most patients, and one of the problems is that the SCD patients are unable to find well-matched donors (Zieve $\&$ Chen, 2011). 
Evidence reveals that thousands of infants and children with HbSS disorders continue dying and many others are suffering severe pain, strokes and other illness episodes due to lack of appropriate medication. Therefore, a reduced child-mortality due to infection and malnutrition is likely to make more babies with genetic disorders survive to present for treatment (Troitskaria et al., 2003). Contributed by social beliefs to a lesser extent, poor family incomes and public health funding contribute to making the overall treatment of this disease remain poor and in some places inadequate (Diallo \& Tchernia, 2002). While this is the situation, another sad news is that many countries' health programmes seem reluctant to include SCD among the priorities for the future, despite efforts made by the WHO and various voluntary agencies to disseminate information about this disease (Weatherall \& Clegg, 2001). The SCA patients face the recurring pain and chronic complications and these interfere with many aspects of the patient's life, including education and employment (WHO, 2009; Hijmans et al., 2009).

The World Health Organization estimates that 70\% of SCA deaths are preventable with simple, cost-effective interventions such as early identification of patients through newborn screening followed by systematic provision of comprehensive care (Makani et al., 2011). SCA among other chronic diseases require a long-term and systematic approach to treatment (WHO, 2005; Aikins et al., 2009). The scientific and technological advances have improved the detection and management of the disease, particularly in the western countries (TSCFT, 2009; WHO, 2009). That is, the identification of risk factors such as infections, low haemoglobin and foetal $\mathrm{Hb}(\mathrm{HbF})$, high white blood cells and haemolysis has led to improved survival of the affected persons through targeted interventions (Makani et al., 2011). Unfortunately, scientific reports reveal that under severe anaemic conditions, blood transfusion is often the immediate alternative medical action (Fabron et al., 1999) and the continuous hemofiltration with dialysis (Kalyanaraman et al., 1999). It is unfortunate that in many cases the patients fail to find people with blood matches (Anie et al., 2010), and leave alone the issue of blood groups, safety of the blood donated is a challenge in the situation of high prevalence of HIV/AIDS and other transfusion-transmittable illnesses (Tshilolo et al., 2007), as well as the stigma people have against blood screening and people found with particular infections (Ubesie et al., 2010; Tagny et al., 2010). Yet, the therapy for SCA is extremely limited both in range, efficacy and scale of use. For instance, in several countries such as those in the west, comprehensive care is reported to include prompt treatment of acute events and prophylaxis against infections, mainly with oral penicillin and vaccination against Streptococcus pneumonia. These have had helped countries to achieve significant reductions in mortality with up to $94 \%$ surviving to 18 years in the USA (Quinn et al., 2006). Patients in many countries are still receiving treatment only for symptom relief of sickle crises painful episodes due to vaso-occlusion by sickle cells (Brugnara et al., 2001). In developed countries, neonatal programmes take care of screening the patients, augmented by oral prophylactic penicillin and effective management of inter-current infections. Moreover, control of strokes using long term transfusion regimens and judicious use of exchange (or top up) transfusion are measures undertaken in those countries. According to experts, these together with an increased understanding of pulmonary and splenic sequestration crises, create hopes that this life-threatening disease is now under some remarkable control (Weatherall \& Clegg, 2001). Sadly, African health systems are weak and national investments in healthcare training and service delivery continue to prioritise infectious and parasitic diseases giving little attention to chronic diseases including SCA (Aikins et al., 2010). Experience shows that while patients with SCA require specialized health centres and life-long medical care and surveillance, many people in resource constrained settings with limited expertise and infrastructure remain at risk of dying helplessly (Weatherall \& Clegg, 2001). Even for the rest of chronic diseases including diabetes, cancer and cardiovascular disorders, it is a fact that many hospitals and clinics lack basic equipment for effective diagnosis and treatment, few health workers have specialist chronic disease training and chronic disease knowledge among health workers is poor in Africa as in many other developing countries (Aikins et al., 2010). 


\section{Evolution in the epidemiological pattern of SCD in Tanzania during the past 50 years}

As reported from elsewhere in SSA, the magnitude of SCA problem is yet to be adequately measured and documented in terms of the scale of its prevalence in Tanzania where diagnostic facilities at primary level health facilities are inadequate (Enevold et al., 2005). Since independence in 1961, a few studies seem to have so far been conducted to establish the magnitude and impact of SCD in Tanzania, so acknowledged is the recent work by Makani et al., (2011) who at least have mainly emphasised research on the clinical epidemiologic dimensions of the disease. The problem of recognition in the medical Diaspora has been reported long time ago in the 1970s when experts observed that due to the ubiquity of the HbS gene in this country, insufficient priority was given to the affected individuals in planning health services (Cochran et al., 1979).

To date, Tanzania ranks number four in the world in terms of number of sickle cell cases, but it is sad that a few Tanzanians know about this disease (Brown, 2010). According to some reporters, rough estimates show the prevalence of the trait in Tanzania ranges between $13 \%$ and $20 \%$ which is among the highest records in Africa, meanwhile, the birth incidence of children with SCD in Tanzania is estimated at 6-7 per 1000 children, implying that within the next five years over 60,000 children would be born with SCD (TSFT, 2009; Makani et al., 2011). However, the magnitude of the prevalence of the trait varies between areas as other reporters establish that the prevalence of sickle cell traits among the Tanzanian population to be as low as $1 \%$ in some communities such as those in the highland areas of north-eastern Tanzania (Enevold et al., 2007). Moreover, over $50 \%$ of children with SCA die before the age of five and among all the recorded infant mortality in Tanzania over $5 \%$ may be attributable to SCD (SCFT, 2009). Other reports reveal that between 4,000 and 6,000 children out of 8,000 children born with the blood disease in Tanzania die before they reach five years (Brown, 2010).

\section{Policies, strategies and interventions for control of SCA in Tanzania}

In Tanzania, as in the rest majority of African countries, there is a general lack of evidence on what is happening at policy level and on the ground regarding prevention, treatment and management of people affected by SCD apart from the general picture that in principle the country embrace the policy established at global level through such multilateral agencies as WHO without having specific country-context policy intervention strategies. Lack of evidence-base (especially locally appropriate information) has led to inertia in terms of implementation of potential care and treatment interventions not only in Tanzania but also in many other countries across the world (Makani et al., 2011). At least recently, a foundation known as The Sickle Cell Foundation of Tanzania (SCFT) has been launched as a non-profit organization devoted to contribute towards prevention, care and effective management of SCA in the country. The Foundation was established in recognition of the devastating impact of this disease on the society and the current inadequacies in its detection, prevention and management. Its mission is to mobilize financial resources and build coalitions to promote and support the setting up of nation-wide sickle cell centres that are responsible for conducting public awareness campaigns on the disease; providing screening and counselling services and treatment and care for sicklecell patients so as to alleviate suffering for those affected by the disease. It also engages itself in supporting research at least in terms of providing technical expertise and carrying out research (TSCFT, 2009: http://sicklecelltz.org).

Recognizing the presence of gaps in the evidence, experts have proposed that baseline data about the clinical course of SCD in the context of African countries are urgently required to inform evidence-based decisions and public sensitization regarding its appropriate management (Sadarangani et al., 2009). At least this disease is one of the six problems listed in the 
government's plan on non-communicable diseases (NCDs) in Tanzania, others being cardiovascular diseases, chronic respiratory diseases, cancers, mental disorders and injuries and trauma (Malecela, 2011) and as part of the broad medium term strategic plan (MTSP) III 2009-2015 which is also part of the broader Tanzanian Vision 2025 (Mosha, 2010). This marks the national/government response to WHO's Call of Action for countries to invest in the prevention and treatment of chronic diseases including SCD (Aikins et al., 2010). Moreover, media sources quoted Prof. David Mwakyusa, the former Minister for Health and Social Welfare in Tanzania assuring the SCFT that the government will support it in recognition of the importance of SCD which despite this disease being uncommonly known yet, the number of people it claims per year is alarming and records show that it is placed number two in terms of number of lives it claims after malaria (Brown, 2010). The government encourages the Tanzanian citizens to use the opportunities available to access the services needed for the control of these problems. Therefore, at least in theory one can see there is a political will from the government's side.

There are also other policies with good intentions in place if they were well interpreted. For instance, understanding the costs associated with seeking medical care services involving payments for the services, the government of Tanzania has for a long time had a policy emphasising exemption of people suffering from specific diseases including diabetes mellitus, hypertension, cancer, asthma and reproductive health related problems from direct user-fee payments $(\mathrm{MoH}, 1993)$. This is an encouraging policy decision as people suffering from these diseases/problems were expected to use the opportunity given to avoid some of the costs they would face if they paid for the services. However, the degree to which exemptions are actually implemented has been found to be unsatisfactory (Newbrander \& Sacca, 1996Mubyazi 2004; Mamdami \& Bangser, 2004). Since the SCD causes frequent illness attacks to individual patients who may need to consult medical care providers regularly, it remains not clear whether or not the service providers can provide the necessary services free of charge to the patients. So far, systematic evidence is lacking about the effectiveness of the user-fee exemption policy in relation to SCD related medical care services. Thus, research is needed to establish whether or not people experiencing SCA are among the beneficiaries from such a national user-fee exemption policy and if not what measures are in place to ensure that the vulnerable individuals are identified, sensitized and motivated to access such a safety-net policy arrangement and actually use the opportunity available.

Interestingly, the government has recognized the shortage of evidence for policy information in this area and emphasized that research should be conducted on this disease and this includes focus on public awareness and the existing strategies for its control (Brown, 2010; Malecela, 2011). Other experts also suggest that analysis of the economic burden of SCD, especially SCA related conditions and informing the national and international health development partners is imperative to allow the planning of the most appropriate and feasible approaches for control, including targeting the right services and at the right time. Researchers are, therefore, urged to play their role of creating evidence that can contribute towards understanding ways of identifying the individuals who genuinely need priority treatment (Weatherall \& Clegg, 2001). In particular, Socio-economic studies are crucial to establish evidence on the cost burdens facing individual SCD patients and their caretakers/families especially in areas where the victims are also vulnerable to malaria, HIV/AIDS, tuberculosis and other communicable and non-communicable diseases.

The effective management and control of any public health problem cannot be achieved if there is no enabling environment for provision of the desired services. This challenge is faced even in the case of SCD. For instance, screening is not currently available for the newborn in Tanzania and patients expect better diagnostic and treatment services at major (referral) hospitals that are mainly urban based (Cox et al., 2011). According to the Sickle Cell Foundation of Tanzania (SCFT), evidence shows that between 50 and $80 \%$ of the children die before the age of five due to ignorance and poor health care 
(http://www.businesstimes.co.tz/index.php?option=com_content\&view). In addition, while there are specialized clinics for patients with SCD at major referral public and private hospitals in the country, there is at most of the health facilities a general shortage of clinicians, haematologists, nurses and laboratory technologists designated/specialized to work in this area throughout the country. This calls for an urgent attention by the authorities concerned to consider intervening and saving the lives of tens and probably hundreds of residents suffering from this disease. Evidence on the residents who are still far away from primary health care facilities, shortage of skilled and motivated human resources for health at most health facilities, especially the peripheral/rural primary level health-care facilities in the country due to supply related constraints continue being revealed (Mubyazi et al., 2012; Manongi et al., 2006; Stringini et al., 2009). From this experience, people living with SCD, especially the SCA patients are facing frequent crises and their families are likely to continue suffering regrettably and helplessly.

\section{Research gaps}

SCD has for decades remained very unpopular in public health programmes and research, both in the developed and developing countries. It has been revealed that even in the United States, laboratory diagnosis of patients with SCA was more done at a later stage in the early 1970 s and there were no definitive treatment to prevent damage and no any safe inexpensive means of making prenatal diagnosis of that condition in the developing foetus (Howard, 2006). Also for other countries, experts have observed that SCD still presents a largely unrecognised health problem for millions of Africans, although Makani et al. (2007) reported that more than a decade has passed since the WHO declared it as a problem of major public-health significance not only for Africa but also for the rest of the continents even if the majority of the patients are found in Africa.

A number of studies have so far been carried out in African countries, but there has been a general lack of a holistic approach used in assessing the burden of SCA across Africa. This has contributed to the observed lack of important evidence-based knowledge and policy on this disease as the basis for designing and implementing appropriate interventions. The available evidence is not sufficient to give the perfect picture on the real burden of the disease in terms of morbidity and mortality since the measures used to reach the estimates reported are not much reliable. One of the reasons is lack of systematic cohort studies that would trace the affected individuals' right from birth through their life end. This would require involving both health facility based and community based study designs and coming up with comparative analyses/results. As such the available information is biased since it is drawn from hospital-based studies alone, thus failing to identify patients with mild disease who do not seek health care from hospitals or those who have died without reporting to health facilities (Makani et al., 2011). In addition, there is a strong consensus that Africa faces significant challenges in chronic disease research, practice and policy while the design of potentially effective interventions would require evidence from multidisciplinary models of research so as to properly inform policy and decision makers (Aikins et al., 2010). It is very unfortunate that Africa is lagging behind other continents in terms of investment in health services and research related to SCA despite having a larger number of people affected by this disease. The expenditure on this disease both in terms of health care and research is negligible. Moreover, policy advance on this disease specifically has not been realized, and most advances in the understanding and management of this condition have been based on the research carried out in the north (Makani et al., 2007). Apparently, even few studies that have been conducted so far in Tanzania have tended to focus on medical dimensions of the disease while there are still psychological, community and policy dimensions of chronic diseases that are yet to be covered.

It is widely evident that malaria is a major cause of admissions and deaths in patients with SCD in SSA and as a result antimalarial prophylaxis is included in the standard management of 
patients with $S C D$ in most countries within the region. The challenge for the time being to researchers and policy decision makers is that for many years chloroquine (CQ) was a drug of choice that provided a cheap, effective, convenient and safe treatment approach. With the spread of drug resistance that led to the replacement of CQ in a country like Tanzania (Mubyazi \& Gonzalez-Block, 2005), and with the increasingly spread of HIV and other opportunistic bacterial infections in the community, there is a considerable debate regarding which drugs should now be recommended for long-term prophylaxis among those with SCD, especially those with the SS genotype who are at risk of dying earlier (Makani et al., 2007). It is unclear how the SCD patients cope with the prevention and treatment environment available given the fact that the availability of CQ is likely to be a conundrum now in the outside markets as are in health facilities. There is therefore a need for exploring how the patients and their caretakers/supporters cope with medication seeking in the environment whereby a prophylaxis is not easily available calls for further systematic evidence.

As for cost analysis, a robust approach is important since the costs associated with any disease should not be looked at from a quantitative approach by ignoring the qualitative dimensions. There is an observation that despite much emphasis on the societal perspective of costing of public health problems as a gold standard in most costing guidelines, most of the costing studies and their associated analyses are still performed from a service provider perspective (Hansen, 2005). In designing the research even in the behavioural field for such a traditionally considered to be 'rare and unpopular disease' like SCA, it is imperative to adhere to the recommended ethical principles or standards (CIOMS, 2002). For instance, due to the reported existence of stigma and discrimination against SCD in some societies (Anie et al., 2010; Ohaeri et al., 1995), researchers have to be careful both in the design of the study questions and the methodology for the administration of the various research instruments so that they can get sufficient cooperation from the target populations. This is so as to avoid causing psychological and social harm to the patients and their families in the communities where the research takes place. A poorly designed and implemented research can cause stigma and discrimination among the patients and families of people with SCA.

\section{Challenges and opportunities for Tanzania}

There are many challenges related to identification, management and prevention/control of the SCD in Tanzania. Shortage of systematic evidence on the prevalence and burden of this disease marks the failure in the policy design for it in the first place. In light of the description given above by drawing evidence from a range of the literature, it can be noted that the key challenges are related to systemic factors such as capacity constraints including shortage of skilled and motivated human resources for delivering the required types of services, especially at primary level and mostly in rural/remote areas; delayed prioritization of the disease among other important non-communicable chronic diseases of reproductive health nature; lack of clear policy strategy specific for this disease which may make it difficult to establish more strategies for its management, control and prevention of its widespread; and poor communication systems and mechanisms that has made the general public and even health-care professionals remain ignorant about the disease nature, management and control aspects for many years; and resource constraint at national level that limit prioritization of the budget for both the disease management and for further research. Other challenges are psychosocial and cultural in nature and are related to stigma and discrimination of the patients with SCD as well as socio-economic in nature such as low public knowledge about the disease, perceived or actual lack of affordability of formal health-care services, and very likely reluctance of some tribes to avoid intra-marriages instead of encouraging inter-tribal or ext-tribal (i.e. beyond one tribe) marriages, to mention some. As for the opportunities, we can argue that the government still have the chance to liaise with the partner organizations in the donor community both from within and abroad to mobilize 
reasonable resources for this disease interventions, supporting basic and operational research on the disease aimed at both establishing a more realistic magnitude of the problem and costeffective and socially desirable/acceptable approaches for its control, increase specialist training of medics and paramedics for better diagnoses and treatment as well as health educationists and advocacy groups for public awareness creation and sensitization on the disease through the best possible communication systems with media involvement and through private-publicpartnerships, and allowing/supporting platform or fora for discussion.

\section{Conclusion}

SCD is partly or greatly neglected not because of being poorly known among many families, communities and national policy/decision makers. It is therefore important to prioritize research on SCD that would provide evidence for decision and policy making. Frontiers in family health affairs including those concerned with marriage matters should be sensitized on this problem and be well informed about appropriate marriage related decisions. This will therefore, help them prepare psychologically and emotionally and take appropriate measures of medical care.

Based on the evidence from a cohort study of children living with SCA in Kilifi, Kenya, Sadarangani et al., (2009) found some similarities and differences between children living with SCD in Africa and their counterparts in the developed world. Nonetheless, there are several areas that require systematic research based on sound methodologies. It is envisaged that research describing the natural course of SCD in sub-Saharan Africa has potential for increasing awareness of the burden of disease and allow appropriate interventions to be instituted. Further research is required to determine the aetiology, pathophysiology and the most appropriate strategies for management of disease, particularly anaemia in SCA (Makani et al., 2011). Research should also be undertaken to establish the survival risks of SCA patients who get blood transfusion in areas that are relatively highly prevalent in HIV/AIDS and the resultant socio-economic burden to the patients and their families. Moreover, future studies need to look at the financial, economic and psychological and social (psychosocial) costs of SCA to patients and their families in a region where there is a high transmission of malaria and other communicable diseases of high policy priority.

It is interesting that some governments including the government of Tanzania have recognized the importance of chronic diseases now more than ever before and are making efforts to ensure that appropriate policies, human resource skills, health facilities and medical care services are available and accessible to the population in need. The implementation of these policies is possible since already in place there are institutions that can be used for training medical and paramedical personnel to work on these problems as well as health facilities through which the services can be delivered. What is required is for the decision and policy makers to continue improving the environment through which the desired services can be delivered to the target users. On the other hand, communities need to be appropriately educated and sensitized on the disease to enable them take appropriate actions for its prevention or taking care of people with SCA. The educational messages should address the psychosocial factors such as cultural values and societal norms since community-level norms and practices shape whether or not people will make best use of medical services (Aikins et al., 2010).

\section{Declaration}

The authors declare no conflict of interest in relation to this paper.

\section{Authors' Contributions}


GMM conceived the paper that was transformed from a research proposal developed two years ago, commented on by $\mathrm{KJN}$ (PhD) before it was transformed into a manuscript with some additional inputs from KJN.

\section{References}

Aikins, A., de-G., Unwin, N., Agyemang, C., Allotey, P., Campbell, C. \& Arhinful D (2010) Tracking Africa's chronic disease burden: from local to global. Globalization and Environment 6:5

Al Arrayed, S. (2005) Campaign to control genetic blood disease in Bahrain. Community Genetics, $8,52-55$.

Anie, K., Egunjobi, F.E. \& Akinyanju, O.O. (2010) Psychosocial impact of sickle cell disorder: perspectives from a Nigerian setting. Globalization and Health 2:6.

Austin, H., Key, N.S., Benson, J.M., Lally, C., Dowling, N.F., Whitsett, C. \& Hooper, C. (2007) Sickle cell trait and the risk of venous thromboembolism among blacks. Blood 110, 908.

Brown, L (2010) More Tanzanians dying of sickle cell disease. East African Business Week, June 2010. http://allafrica.com/stories/201006220489.html (accessed on 25 November, 2011).

Brugnara, C., Franceschi, L.D., Bennekou. P., Alper. S.L. \& Christophersen, P. (2001) Novel therapies for prevention of erythrocyte dehydration in sickle cell anaemia. Drug News Perspective 14, 208.

Buchanan, G., Vichinskym E., Krishnamurti, L. \& Shalini, S. (2011) Severe sickle cell disease pathophysiology and therapy. Blood Marrow Transplant 16 (1 Suppl): S64-S67.

CIOMS (2002) International Ethical Guidelines for Biomedical Research Involving Human Subjects. Council for International Organisations of Medical Sciences (CIOMS), ISBN 9290360755

Cochrane Library (2009) Regular blood transfusion to prevent stroke in people with sickle cell disease. John Wiley \& Sons, Inc.

Cox, S.E., Makani, J., Fulford, A.J., Komba, A.N., Soka, D., Williams, T.N., Newton, C.R., March, K. \&

Prentice, A. (2011) Nutritional status, hospitalization and mortality among patients with sickle cell anemia in Tanzania. Haematologica 96, 948-953.

Diallo, D. \& Tchernia, G. (2002). Sickle cell disease in Africa. Current Opinion in Hematology 9, 111-6

Diallo, D.A. (2008) Sickle cell disease in Africa: current situation and strategies for improving the quality and duration of survival. Bulletin de l'Academie Nationale de Medecine 192, 1361-1377.

Enevold, A., Vestergaard, L.S., Lusingu, J., Drakeley, C.J., Lemnge, M.M., Theander, T., Bygbjerg, I.C. \& Alifangis, M. (2005) Rapid screening for glucose-6-phosphate dehydrogenase deficiency and haemoglobin polymorphisms in Africa by a simple high-throughput SSOPELISA method. Malaria Journal 4:61.

Fleming, A.F. (2009) The presentation, management and prevention of crisis in sickle cell disease in Africa. Blood Review 3(1): 18-28.

Golden, W.E. \& Moore, G. (2004) Misdiagnosis can affect treatment. Journal of Arkansas Medical Society $10,144-145$.

Grosse, S.D., Odame, I., Atrash, H.K., Amendah, D.D., Piel, F.B. \& Williams, T.N. (2011) Sickle cell disease in Africa: a neglected cause of early childhood mortality. American Journal of Preventive Medicine 41(Suppl 4), S398-405.

Hansen, K.S. (2005) Using disability-adjusted life years and cost-effectiveness analysis to define priorities for the public health care sector in Zimbabwe. PhD Thesis, Department of Economics, University of Copenhagen, DK

Haque, A. \& Telfair, J. (2000) Socioeconomic distress and health status: The urban-rural dichotomy for people with sickle cell disease in North Carolina. Journal of Rural Health, 16, 43-55.

Harvard University (2002) Hemoglobinopathies (Hemoglobin Disorders). http://sickle.bwh.harvard.edu/hemoglobinopathy.html (accessed: 5th March, 2012). 
Hijmans, C., Grooenhuis, M.A., Oosterlaan, J., Last, B.F., Heijboer, H., Peters, M. \& Fijnvandraat, K. (2009) Behavioral and Emotional Problems in Children With Sickle Cell Disease and Healthy Siblings: Multiple Informants, Multiple Measures. Pediatric Blood Cancer 53, 12771283.

Hijmans, C.T., Fijnvandraat, K., Oosterlaan, J., Heijboer, H., Peters, M. \& Grootenhuis, M.A. (2010) Double disadvantage: a case control study on health-related quality of life in children with sickle cell disease. Health and Quality of Life Outcomes 8:121.

Howard, M. (2006) Promoting safe and effective genetic testing in the US: Appendix 6: Scientific advances and social risks: Historical perspectives of genetic screening programs for sickle cell disease, Tay Sachs Disease, Neural Tube. National Institute of Health. http://www.genome.gov/10002401 (accessed: 10th March 2012).

Jenerette, C. \& Lauderdale, G. (2008) A successful aging with sickle cell disease: Using qualitative Methods to Inform Theory. Journal of Theory Construction and Testing 12(1): 16-24

Kalyamaraman, M., Hedemann, S.M., Sarnaik, A.P., Meert, K.L. \& Sarnaik, S.A. (1999) Anti-s antibody-associated delayed hemolytic transfusion reaction in patients with sickle cell anaemia. Journal of Pediatric Hematology/ Oncology 21, 70-73.

Makani, J., Cox, S., Soka, D., Komba, A.N., Uruo, J., Mwamtemi, H., Magesa, P., Rwazaula, S>, Meda, E., Mgaya, J. et al, (2011) Mortality in Sickle Cell Anemia in Africa: A prospective cohort study in Tanzania. PloS One 6 (2): DOI: 10.1371/journal.pone.0014699

Makani, J.K., Komba, A.N., Cox, S.E., Oruo, J., Mwamtemi, K., Kitundu, J., Magesa, P., Rwezaula, S., Meda, E., Mgaya, J., et al. (2009) Malaria in patients with sickle cell anemia: burden, risk factors and outcome at outpatient clinic and during hospitalization. Blood 115, 215-220.

Makani, J., Williams, T.N. \& Marsh, K. (2007) Sickle cell disease in Africa: burden and research priorities. Annals of Tropical Medicine and Parasitology 101, 3-4

Malecela, M.N. (2011) Non-communicable diseases in Tanzania. A paper presented at the International Association of Public Health Institute, $10^{\text {th }}$ March, 2011

Mamdami, M. \& Bangser, M. (2004) Poor people's experiences of health services in Tanzania: a literature review. Women's Dignity Project, http://www.womensdignity.org/Peoples_experience.pdf (accessed: 20th November 2011).

Manongi, R., Marchant, C.T. \& Bygbjerg, I.C. (2006) Improving motivation among primary health care workers in Tanzania: a health worker perspective. Human Resources for Health 4:6

Martin, L.G. \& Soldo, B.J. (1997) Two Simple Monogenic Disorders Differing in Frequency In Blacks and Whites. P 211. In: Racial and Ethnic Differences in the Health of Older Americans, pp 312.

MoHSW (2010) Ministry of Health and Social Welfare: Tanzania National Non-communicable Diseases (NCDs) Strategy: Preventing NCDs. Seminar 15-19, March 2010, Helsinki, Finland. www.ktl.fi/attachments/ncd_seminar_2010/tansania_ncd_strategy.ppt $\quad$ (Accessed: $8^{\text {th }}$ March 2012).

Mubyazi, G.M. \& Gonzalez-Block, M.A. (2005) Research influence on antimalarial drug policy change in Tanzania: case study of replacing chloroquine with sulfadoxine-pyrimethamine as first line drug. Malaria Journal 5:51.

Mubyazi, G.M. (2004) The Tanzanian policy on health-care fee waivers and exemptions in practice as compared with other developing countries: evidence from recent local studies and international literature. East African Journal of Public Health 1(1):1-10.

Mubyazi, G.M., Byskov, J., Magnussen, P., Bygbjerg, I.C. \& Hansen, K.S. (2012) Supply-related drivers of staff motivation for providing intermittent preventive treatment of malaria during pregnancy in Tanzania: evidence from two rural districts. Malaria Journal 11:48.

Mubyazi, G.M., Magnussen, P., Goodman, C., Bygbjerg, I.C., Kitua, A.Y., Olsen, Ø.E., Byskov, J., Hansen, K.S. \& Bloch, P. (2008) Implementing intermittent preventive treatment for malaria during pregnancy: review of prospects, achievements, challenges and agenda for research. Open Tropical Medicine Journal, 1:92-100 
Mvundura, M., Amendah, D., Kavanagh, P.L., Sprinz, P.G. \& Grosse, S.D. (2009) Health care utilization and expenditures for privately and publicly insured children with sickle cell disease in the United States. Pediatric Blood \& Cancer 53, 642-646.

Newbrander, W. \& Sacca, S. (1996) Equity experiences in Tanzania. Draft Report. A Technical Research Report submitted to Bureau for Africa Office on Sustainable Development, and for The Health and Human Resources Analysis in Africa (HHRAA) Project, USAID and MoH, Tanzania

Ohaeri, J.U., Shokunbi, W.A., Akindale, K.S. \& Dare, L.O. (1995) The psychosocial problems of sickle cell disease sufferers and their methods of coping. Social Science and Medicine 40, 955960.

Piel, F.B., Patil, A.P., Howes, R.E., Nyangiri, O.A., Gething, P.W., Williams, T., Weatherall, D.J. \& Hay, S. (2010) Global distribution of the sickle cell gene and geographical confirmation of the malaria hypothesis. Nature Communications 2, 104.

Quinn, C.T., Rogers, Z.R. \& Buchanan, G.R. (2004) Survival of children with sickle cell disease. Blood 103, 4023-4027.

Sadarangani, M., Makani, J., Komba, A.N., Ajala-Agbo, T., Newton, C.R., Marsh, K. \& Williams, T.N. (2009) An observational study of children with sickle cell disease in Kilifi, Kenya. British Journal of Haematology 146, 675-682.

Stringhini, S., Thomas, S., Bidwell, P., Mtui, T. \& Mwisongo, A. (2009) Understanding informal payments in health care: motivation of health workers in Tanzania. Human Resources for Health, 7:53.

Tagny, C.T., Owusu-Ofori, S.D., Mbanya, D. \& Deneys, V. (2010) The blood donor in sub-Saharan Africa. Transfusion Medicine 20, 1-10.

The Sickle Cell Foundation of Tanzania, 2009. http://www.sicklecelltz.org (accessed on 25 November, 2011).

Troitskaria, O.V., lushkova, N.M., Ivanova, N.A. \& Kuznetsov, V.I. (2003) Sickle cell anaemia (HBSS) in an adult patient from Tanzania. Klinicheskaia Laboratornaia Diagnostika 6: 21-31.

Tshilolo, L.M., Mukendi, R.K. \& Wembonyama, S.O. (2007) Blood transfusion rate in Congolese patients with sickle cell anemia. Indian Journal of Paediatrics 74, 735-738

Ubesie, A.C., Emodi, I.J. \& Ikefuna, A.N. (2010) High incidence of blood transfusion-related HIV infection in Nigeria. Internet Journal of Haematology 7, 16.

Valentine, W.N., Tanaka, K.R. \& Paglia, D.E. (1985) Hemolytic anemias and erythrocyte enzymopathies. Annals of Internal Medicine 103, 245-257.

van den Tweel., X.W., Hatzmann, J., Ensink, E., van der Lee J., Peters, M., Fijnvandraat, K. \& Grootenhuis, M. (2008) Quality of life of female caregivers of children with sickle cell disease: a survey. Decision Making and Problem Solving 93:4

Vichinsky, E.P., Luban. N.L., Wright. E., Olivieri. N., Driscoll. C., Pegelow. C/H. \& Adams, R.J. (2002) Prospective RBC phenotype matching in a stroke-prevention trial in sickle cell anaemia: a multicentre transfusion trial. Transfusion, 42(5):658-9

Weatherall, D.J. \& Clegg, J.B. (2001) Inherited haemoglobin disorders: an increasing global health problem. Bulletin of the World Health Organization 79, 704-712.

WHO (2005) Preventing Chronic Disease: A vital investment. World Health Organization, Geneva.

WHO (2006) Management of Birth Defects and Haemoglobin Disorders: Report of a Joint WHOMarch of Dimes Meeting. World Health Organization, Geneva.

WHO (2009) Sickle Cell Disease Prevention and Control. WHO African Region, Country Office, Kenya, Nairobi. http://www.afro.who.int/en/kenya/kenya-publications/1775-sickle-celldisease.html.

Zieve, D. \& Chen, Y.B. (2011) Sickle cell anemia: Anemia - sickle cell; Hemoglobin SS disease (Hb SS); Sickle cell disease. A.D.A.M Inc., http://www.ncbi.nlm.nih.gov/pubmedhealth/PMHoo01554/ 